\title{
Motivasi Sebagai Mediasi Pengaruh Pelatihan Dan Lingkungan Kerja Terhadap Kinerja Pegawai Medis Instalasi Rawat Inap B RSUP Sanglah Denpasar
}

\author{
Wayan Arya Paramarta ${ }^{(1)}$ \\ I Putu Purnama Astika ${ }^{(2)}$ \\ (1)(2) Program Studi Manajemen, Sekolah Tinggi Ilmu Manajemen Indonesia Handayani \\ e-mail: aryaajus@gmail.com

\begin{tabular}{|l|l|l}
\hline Diterima: 7 Juli 2020 & Direvisi: 22 Juli 2020 & Disetujui: 30 Juli 2020
\end{tabular}

\begin{abstract}
This study aimed to explain the effect of work training and work environment on the performance of medical staff Inpatient Installation B Sanglah General Hospital Denpasar through motivation as an intervening variable. The type of data used in this study is qualitative and quantitative data, with data sources namely primary and secondary data. The data collection method is an interview, distributing questionnaires to respondents and library research, while the data analysis technique used Smart PLS 3.2.9. The results of this study showed that work training had a positive effect but not significant on motivation, work environment had a positive effect and significant on motivation, work training had a positive effect and significant on performance, work environment had a positive effect but not significant on performance, motivation had a positive effect but not significant on performance, work training had a positive effect but not significant on performance through motivation, work environment had a positive effect but not significant on performance through motivation medical staff Inpatient Installation B Sanglah General Hospital Denpasar.
\end{abstract}

Keywords: Work Training, Work Environment, Performance and Motivation.

\section{Pendahuluan}

Pesatnya perkembangan ilmu pengetahuan dan teknologi membuat organisasi harus mampu beradaptasi dengan perubahan baik perubahan yang berasal dari dalam maupun dari luar organisasi. Kemampuan organisasi atau perusahaan dalam menghadapi perubahan akan berdampak pada kelangsungan hidup organisasi. Rumah Sakit sebagai salah satu organisasi bentuk layanan jasa yang kompleks, dinamis, kompetitif, padat modal, padat karya dan multi disiplin.

Menurut WHO (World Health Organization), rumah sakit adalah bagian integral dari suatu organisasi sosial dan kesehatan dengan fungsi menyediakan pelayanan paripurna (komprehensif), penyembuhan penyakit (kuratif) dan pencegahan penyakit (preventif) kepada masyarakat. Rumah sakit juga merupakan pusat pelatihan bagi tenaga kesehatan dan pusat penelitian medik. (Rikomah, 2017). 
RSUP Sanglah Denpasar sebagai unit pelayanan kesehatan masyarakat mempunyai visi menjadi rumah sakit rujukan nasional kelas dunia dan mempunyai misi menyelenggarakan pelayanan kesehatan interprofesi yang paripurna, bermutu untuk seluruh lapisan masyarakat, menyelenggarakan pendidikan tenaga kesehatan yang profesional dan berdaya saing serta menyelenggarakan penelitian dalam bidang kesehatan berbasis rumah sakit, menyelenggarakan kemitraan dengan pemangku kesehatan terkait dan menciptakan lingkungan kerja yang aman dan nyaman.

Agar pelayanan di dalam sebuah perusahaan mengalami peningkatan mutu dan kualitas yang baik, perusahaan memberikan suatu pelatihan kerja yang maksimal. Melalui program pelatihan yang cukup dan sesuai untuk kebutuhan pegawai, maka pegawai akan semakin memahami dan menguasai dalam menjalankan profesinya dan pada gilirinnya kinerjanyapun semakain baik.

Pernyataan ini sejalan dengan hasil penelitian sebelumnya oleh (Paramarta \& Kasih, 2018) menunjukkan bahwa pelatihan berpengaruh signifikan terhadap kinerja karyawan. Hal yang sama juga dikemukakan oleh (Andayani \& Makian, 2016) bahwa pelatihan kerja dapat memberikan tambahan pengetahuan dalam menyelesaikan pekerjaan secara efektif dan berpengaruh terhadap kinerja karyawan. Namun hasil penelitian berbeda ditunjukkan oleh (Randy, 2016) bahwa pelatihan berpengaruh negatif terhadap kinerja karyawan.

Dalam melakukan tugas atau pekerjaan para pegawai membutuhkan lingkungan kerja yang kondusif, dimana lingkungan kerja tersebut dapat membantu pegawai dalam melakukan perkerjaannya sesuai dengan prosedur perusahaan. Lingkungan kerja yang memenuhi standar kebutuhan layak akan memberikan kontribusi pada kenyamanan pegawai dalam menjalankan pekerjaanya, sikap ramah pegawai, saling menghargai saat berbeda pendapat, hubungan yang harmonis antara pegawai dan pimpinan yang merupakan syarat wajib untuk dibina sehingga kualitas pemikiran pegawai pada akhirnya dapat meiningkatkan kinerja secara terus menerus.

Pernyataan ini sejalan dengan hasil penelitian sebelumnya oleh (Chandra \& Setiawan, 2018) menunjukkan bahwa lingkungan kerja berpengaruh positif terhadap semangat kerja karyawan. Hal yang sama juga dikemukakan oleh (Pratama \& Wismar'ein, 2018, Putri, 2019) bahwa lingkungan kerja berpengaruh positif dan signifikan terhadap kinerja pegawai. Namun hasil penelitian berbeda ditunjukan oleh (Mamangkey et al., 2015) bahwa lingkungan kerja tidak berpengaruh terhadap kinerja karyawan.

Selain pelatihan dan lingkungan kerja, motivasi juga berperan penting dalam mendorong semangat kerja pegawai untuk mencapai tujuan organisasi. Menurut (Batjo \& Shaleh, 2018) Motivasi adalah suatu usaha sadar untuk mempengaruhi perilaku seseorang supaya mengarah 
tercapainya tujuan organisasi. Motivasi kerja memegang peranan penting dalam menentukan berhasil tidaknya seseorang dalam melaksanakan tugas yang dibebankan kepadanya.

Pokok masalah yang diajukan dalam penelitian ini adalah bagaimana pengaruh pelatihan dan lingkungan kerja terhadap kinerja pegawai medis Instalasi Rawat Inap B RSUP Sanglah Denpasar yang di mediasi oleh variabel motivasi. Sedangkan yang menjadi tujuan dalam penelitian ini adalah untuk menjelaskan pengaruh pelatihan dan lingkungan kerja terhadap kinerja pegawai medis Instalasi Rawat Inap B RSUP Sanglah Denpasar yang di mediasi oleh variabel motivasi.

\section{Telaah Literatur dan Kajian Pustaka}

\section{Pelatihan Kerja}

Mangkunegara (2008) mengemukakan bahwa pelatihan adalah suatu proses pendidikan jangka pendek yang mempergunakan prosedur sistematis dan terorganisir dimana pegawai non manajerial mempelajari pengetahuan dan keterampilan teknis dalam tujuan terbatas (Prasetyo \& Nurbiyati, 2019).

Menurut Mangkunegara (2013), pelatihan dibagi menjadi enam indikator yaitu sebagai berikut (Sudaryo et al., 2018) :

1. Instruktur, mengingatkan pelatihan umumnya berorientasi pada peningkatan skill, maka para pelatih yang dipilih untuk memberikan materi pelatihan harus benar-benar memiliki kaulifikasi yang memadai sesuai dengan bidangnya, profesional dan berkompeten, selain itu pendidikan instruktur pun harus benar-benar baik untuk melakukan pelatihan.

2. Peserta pelatihan, peserta pelatihan tentunya harus diseleksi berdasarkan persyaratan tertentudan kualifikasi yang sesuai, selain itu peserta pelatihan juga harus memiliki semangat yang tinggi untuk mengikuti pelatihan.

3. Materi, pelatihan sumber daya manusia merupakan materi atau kurikulum yang sesuai dengan tujuan pelatihan sumber daya manusia yang hendak dicapai oleh perusahaan dan materi pelatihan pun harus update agar si peserta dapat memahami masalah yang terjadi pada kondisi yang sekarang.

4. Metode, metode pelatihan akan menjamin berlangsungnya kegiatan pelatihan sumber daya manusia yang efektif, apabila sesuai dengan jenis materi dan komponen peserta pelatihan.

5. Tujuan pelatihan, pelatihan memerlukan tujuan yang telah ditetapkan, khususnya terkait dengan penyusunan rencana aksi (action plan) dan penetapan sasaran, serta hasil yang diharapkan dari pelatihan yang diselenggarakan. Tujuan pelatihan juga harus disosialisasikan sebelumnya kepada para peserta, agar peserta dapat memahami pelatihan tersebut. 
6. Sasaran, sasaran pelatihan harus ditentukan dengan kriteria yang terperinci dan terukur (measurable).

\section{Lingkungan Kerja}

Soetjipto (2008) mengemukakan bahwa, lingkungan kerja adalah segala suatu hal atau unsur-unsur yang dapat mempengaruhi secara langsung maupun tidak langsung terhadap organisasi atau perusahaan yang akan memberikan dampak baik atau buruk terhadap kinerja dan kepuasan kerja karyawan (Anugrah \& Abdurrahman, 2019). Sedarmayanti (2009:26) dalam (Norianggono et al., 2014) menyatakan bahwa secara garis besar, lingkungan kerja terdapat dua jenis yaitu:

1. Lingkungan Kerja Fisik, yaitu semua keadaan berbentuk fisik yang terdapat di sekitar tempat kerja dimana dapat mempengaruhi pegawai baik secara langsung maupun tidak langsung. Lingkungan kerja fisik sendiri dapat dibagi dalam dua kategori. Kategori yang pertama adalah lingkungan yang berhubungan langsung dengan pegawai dan berada di dekat pegawai (seperti meja, kursi dan sebagainya). Kategori yang kedua adalah lingkungan perantara atau lingkungan umum dapat juga disebut lingkungan kerja yang mempengaruhi kondisi manusia, misalnya: temperatur, kelembaban, sirkulasi udara, pencahayaan, kebisingan, getaran mekanis, bau tidak sedap, warna, dan lain-lain.

2. Lingkungan Kerja Non Fisik adalah lingkungan kerja yang menyenangkan dalam arti terciptanya hubungan kerja yang harmonis antara pegawai dan atasan, karena pada hakekatnya manusia dalam bekerja tidak hanya mencari uang saja, akan tetapi bekerja merupakan bentuk aktivitas yang bertujuan untuk mendapatkan kepuasan.

\section{Motivasi}

Hasibuan (2009) menyatakan bahwa motivasi dapat dikatakan sebagai suatu cara bagaimana mendorong gairah kerja bawahannya agar mereka mau bekerja keras dengan memberikan semua kemampuan dan ketrampilannya untuk mewujudkan tujuan perusahaan (Putra et al., 2017). Metode motivasi ada dua metode, yaitu sebagai berikut (Iskandar \& Yuhansyah, 2018) :

1. Motivasi langsung, langsung adalah motivasi yang diberikan secara langsung kepada setiap individu karyawan/pegawai untuk memenuhi kebutuhan serta kepuasannya. Jadi sifatnya khusus, seperti pujian, penghargaan, tunjangan hari raya, bonus, dan lain-lain.

2. Motivasi tidak langsung, motivasi ini yang diberikan hanya merupakan fasilitas-fasilitas yang mendukung serta menunjang gairah kerja/kelancaran tugas sehingga para pegawai betah dan bersemangat melakukan pekerjaannya. Motivasi tidak langsung besar pengaruhnya untuk 
merangsang semangat bekerja pegawai sehingga produktif. Misalnya ruangan kerja yang tenang dan nyaman, suasana pekerjaan, penempatan yang tepat, dan lain-lain.

\section{Kinerja}

Widodo (2015) mengemukakan bahwa kinerja adalah tingkatan pencapaian hasil atas pelaksanaan tugas tertentu. Kinerja individu sebagai tingkat pencapaian hasil kerja seseorang dari sasaran yang harus dicapai atau tugas yang harus dilaksanakan dalam kurun waktu tertentu. (Ramadhan, 2018).

Adapun faktor-faktor yang mempengaruhi kinerja menurut Simanjuntak dalam (Widodo, 2015) adalah sebagai berikut:

1. Kualitas dan kemampuan pegawai, yaitu hal-hal yang berhubungan dengan pendidikan/pelatihan, etos kerja, motivasi kerja, sikap mental, dan kondisi fisik pegawai.

2. Sarana pendukung, yaitu hal-hal yang berhubungan dengan lingkungan kerja (keselamatan kerja, kesehatan kerja, sarana produksi, teknologi) dan hal-hal yang berhubungan dengan kesejahtraan pegawai (upah/gaji, jaminan sosial, keamanan kerja).

3. Supra sarana, yaitu hal-hal yang berhubungan dengan kebijakan pemerintah dan hubungan industrial manajemen.

\section{Hipotesis}

Dalam penelitian ini dapat dirumuskan beberapa hipotesis yang nantinya akan diuji kebenarannya melalui penelitian ini sebagai berikut: $\mathrm{H}_{1}$. Pelatihan berpengaruh positif dan signifikan terhadap motivasi pegawai medis Instalasi Rawat Inap B RSUP Sanglah Denpasar; $\mathrm{H}_{2}$. Lingkungan Kerja berpengaruh positif dan signifikan terhadap motivasi pegawai medis Instalasai Rawat Inap B RSUP Sanglah Denpasar; $\mathrm{H}_{3}$. Pelatihan berpengaruh positif dan signifikan terhadap kinerja pegawai medis Instalasi Rawat Inap B RSUP Sanglah Denpasar; $\mathrm{H}_{4}$. Lingkungan kerja berpengaruh positif dan signifikan terhadap kinerja pegawai medis Instalasi Rawat Inap B RSUP Sanglah Denpasar; H5. Motivasi berpengaruh positif dan signifikan terhadap kinerja pegawai medis Instalasi Rawat Inap B RSUP Sanglah Denpasar; $\mathrm{H}_{6}$. Pelatihan berpengaruh positif dan signifikan terhadap kinerja melalui motivasi pegawai medis Instalasi Rawat Inap B RSUP Sanglah Denpasar dan $\mathrm{H}_{7}$. Lingkungan Kerja berpengaruh positif dan signifikan terhadap kinerja melalui motivasi pegawai medis Instalasi Rawat Inap B RSUP Sanglah Denpasar.

\section{Metode Penelitian}

Penelitian ini dilakukan di Instalasi Rawat Inap B RSUP Sanglah Denpasar dengan responden seluruh pegawai medis baik itu perawat dan bidan di Instalasi Rawat Inap B RSUP Sanglah Denpasar sebanyak 168 orang. Pengambilan sampel dalam penelitian ini menggunakan 
metode Simple Random Sampling, dimana semua populasi memiliki kesempatan yang sama untuk dipilih menjadi sampel dan rumus yang digunakan dalam penentuan sampel adalah rumus Slovin sehingga terpilih 63 orang sebagai responden.

Berdasarkan tinjauan pustaka, tahapan penelitian serta hipotesis penelitian, maka dapat diidentifikasikan variabel-variabel penelitian sebagai berikut:

1. Pelatihan kerja $\left(\mathrm{X}_{1}\right)$ adalah sebuah proses pembelajaran yang memungkinkan pegawai medis Instalasi Rawat Inap B RSUP Sanglah Denpasar mengubah tingkah laku atau memperbaiki kemampuan kerja dalam berkerja dan meningkatkan pengetahuan, keterampilan, kecakapan serta sikap pegawai yang diperlukan didalam mencapai tujuan dari sebuah organisasi. Dengan indikator menurut Mangkunegara (2013) dalam (Sudaryo et al., 2018) sebagai berikut: 1) Instruktur; 2) Peserta; 3) Materi; 4) Metode; 5) Tujuan dan 6) Sasaran.

2. Lingkungan kerja $\left(\mathrm{X}_{2}\right)$ 1)Lingkungan kerja merupakan segala sesuatu yang ada disekitar pegawai medis instalasi Rawat inap B RSUP Sanglah Denpasar pada saat bekerja, baik yang berbentuk fisik maupun non fisik yang dapat mempengaruhi secara langsung maupun tidak langsung dan akan memberikan dampak baik atau buruk terhadap kinerja dan kepuasan kerja pegawai. Dengan indikator menurut Sedarmayanti (2009:46) dalam (Budianto \& Katini, 2015) sebagai berikut: 1) Penerangan; 2) Suhu Udara; 3) Suara Bising; 4) Penggunaan Warna; 5) Ruang Gerak; 6) Kemampuan dan 7) Hubungan Pegawai.

3. Motivasi $\left(\mathrm{Y}_{1}\right)$ adalah adalah dorongan dari dalam diri maupun dari luar diri pegawai medis Instalasi Rawat Inap B RSUP Sanglah Denpasar, yang dapat dikembangkannya sendiri atau dikembangkan oleh sejumlah kekuatan luar baik secara positif maupun negatif guna untuk mencapai suatu tujuan yang sudah ditentukan dalam sebuah organisasi. Dengan indikator menurut George dan Jones (2005) dalam (Lusri \& Siagian, 2017) sebagai berikut : 1) Arah Prilaku; 2) Tingkat Usaha dan 3) Tingkat Kegigihan.

4. Kinerja $\left(\mathrm{Y}_{2}\right)$ adalah adalah pencapaian hasil kerja pegawai medis Instalasi Rawat Inap B RSUP Sanglah Denpasar secara kualitas dan kuantitas yang harus dicapai dalam kurun waktu tertentu oleh seorang pegawai didalam melaksanakan tugasnya sesuai dngan tanggung jawab yang diberikan kepadanya. Dengan indikator dari Suwondo dan Sutanto (2015) dalam (Lusri \& Siagian, 2017) sebagai berikut : 1) Ketepatan; 2) Tingkat Inisiatif; 3) Kecekatan Mental serta 4) Kedisiplinan Waktu dan Absensi.

Penelitian ini menggunakan analisis PLS dengan dua variabel bebas dan dua variabel terikat, dimana satu variabel merupakan variabel intervening. Berikut model dalam penelitian ini: 


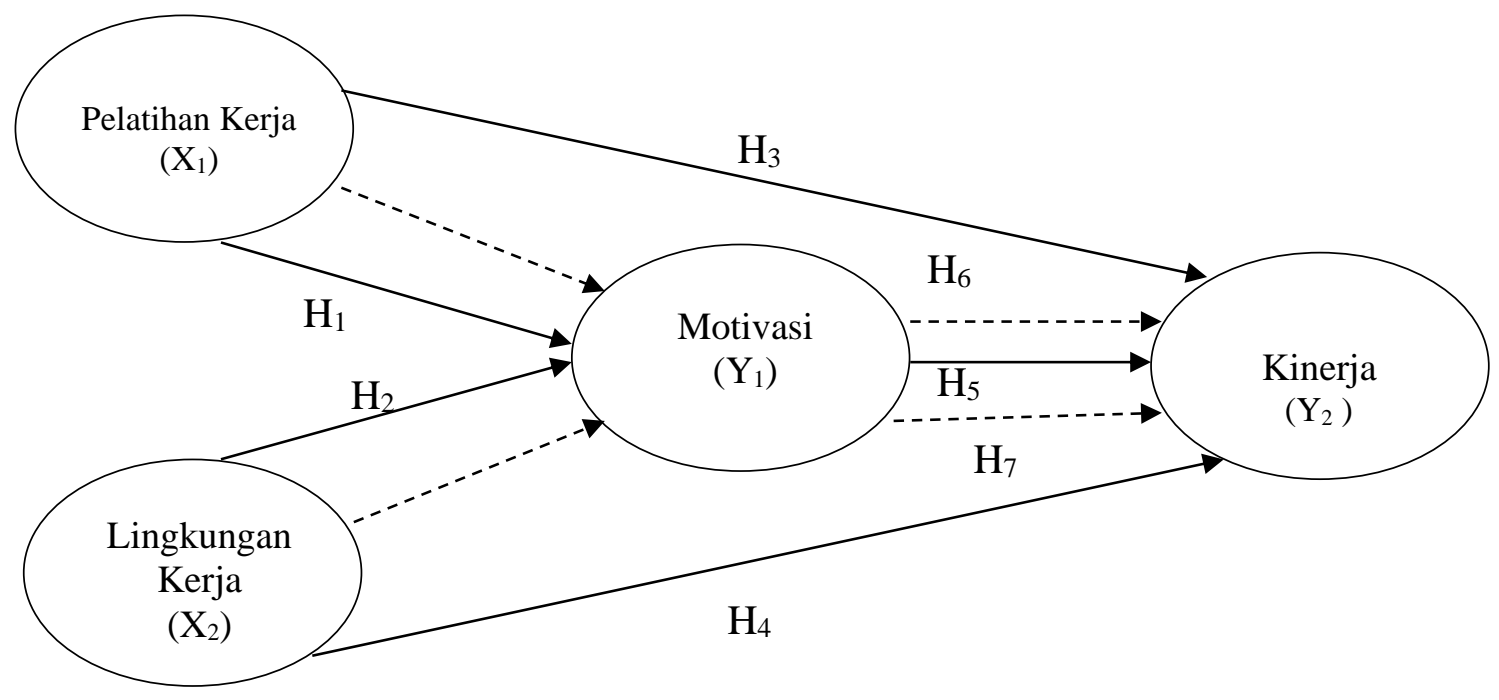

Gambar 1. Model Penelitian

Dalam penelitian ini peneliti menggunakan teknik pengumpulan data berupa penyebaran kuisioner atau angket. Kuesioner/angket adalah teknik pengumpulan data yang dilakukan dengan cara memberikan seperangkat pertanyaan atau pernyataan kepada orang lain yang dijadikan responden untuk dijawabnya. Dari kuesioner dapat dihasilkan hasil jawaban yang disebarkan kepada responden.

Setelah data terkumpul dari lapangan, selanjutnya dilakukan pengolahan terlebih dahulu agar data yang tersebar luas dalam item-item kuesioner dapat dibuat lebih ringkas dan lebih sederhana dengan bantuan program IBM SPSS Statistics 22. Selanjutnya, analisis dilakukan agar data mentah yang diperoleh di lapangan mempunyai arti dan makna sehingga dapat menjawab permasalahan yang diajukan, analisis data dalam penelitian ini dilakukan dengan menggunakan Smart PLS 3.2.9. 


\section{Hasil Penelitian dan Pembahasan}

\section{Tabel 1. Hasil Output Uji Validitas dan Reliabilitas Instrumen}

\begin{tabular}{|c|c|c|c|c|}
\hline Variabel & $\begin{array}{c}\text { Cronbach's } \\
\text { Alpha }\end{array}$ & Indikator & $\begin{array}{c}\text { Koefisien } \\
\text { Korelasi }\end{array}$ & Keterangan \\
\hline $\begin{array}{l}\text { Pelatihan Kerja } \\
\qquad\left(\mathrm{X}_{1}\right)\end{array}$ & $\begin{array}{c}0,755 \\
\text { (Reliabel) }\end{array}$ & $\begin{array}{l}\text { Instruktur } \\
\text { Peserta } \\
\text { Materi } \\
\text { Metode } \\
\text { Tujuan } \\
\text { Sasaran }\end{array}$ & $\begin{array}{l}0,545 * * \\
0,680 * * \\
0,760 * * \\
0,726 * * \\
0,743 * * \\
0,566 * *\end{array}$ & $\begin{array}{l}\text { Valid } \\
\text { Valid } \\
\text { Valid } \\
\text { Valid } \\
\text { Valid } \\
\text { Valid }\end{array}$ \\
\hline $\begin{array}{l}\text { Lingkungan Kerja } \\
\qquad\left(\mathrm{X}_{2}\right)\end{array}$ & $\begin{array}{c}0,631 \\
\text { (Reliabel) }\end{array}$ & $\begin{array}{l}\text { Penerangan } \\
\text { Suhu } \\
\text { Kebisingan } \\
\text { Warna } \\
\text { Gerak } \\
\text { Kemampuan } \\
\text { Hubungan }\end{array}$ & $\begin{array}{l}0,503^{* *} \\
0,338^{* *} \\
0,550^{* *} \\
0,496^{* *} \\
0,601^{* *} \\
0,575^{* *} \\
0,559^{* *}\end{array}$ & $\begin{array}{l}\text { Valid } \\
\text { Valid } \\
\text { Valid } \\
\text { Valid } \\
\text { Valid } \\
\text { Valid } \\
\text { Valid }\end{array}$ \\
\hline $\begin{array}{l}\text { Motivasi } \\
\quad\left(\mathrm{Y}_{1}\right)\end{array}$ & $\begin{array}{c}0,669 \\
\text { (Reliabel) }\end{array}$ & $\begin{array}{l}\text { Prilaku } \\
\text { Usaha } \\
\text { Kegigihan }\end{array}$ & $\begin{array}{l}0,733^{* *} \\
0,680^{* *} \\
0,682^{* *}\end{array}$ & $\begin{array}{l}\text { Valid } \\
\text { Valid } \\
\text { Valid }\end{array}$ \\
\hline $\begin{array}{l}\text { Kinerja } \\
\left(\mathrm{Y}_{2}\right)\end{array}$ & $\begin{array}{c}0,643 \\
\text { (Reliabel) }\end{array}$ & $\begin{array}{l}\text { Ketepatan } \\
\text { Inisiatif } \\
\text { Mental } \\
\text { Waktu }\end{array}$ & $\begin{array}{l}0,596^{* *} \\
0,673^{* *} \\
0,587^{* *} \\
0,598^{* *}\end{array}$ & $\begin{array}{l}\text { Valid } \\
\text { Valid } \\
\text { Valid } \\
\text { Valid }\end{array}$ \\
\hline
\end{tabular}

Sumber: Data diolah

Berdasarkan rekapitulasi hasil perhitungan nilai korelasi product moment dari tiap-tiap item pertanyaan/pernyataan pada Tabel 1 , diperoleh hasil yang besarnya di atas 0,3 . Hal ini berarti semua butir pertanyaan/pernyataan dalam kuesioner tersebut dapat dikatakan valid. Berdasarkan rekapitulasi hasil perhitungan nilai cronbach's alpha dari masing-masing variabel pada Tabel 1 diperoleh hasil yang besarnya di atas 0,60 . Hal ini berarti semua variabel dalam kuesioner tersebut dapat dikatakan reliabel.

Dalam penelitian ini, teknik analisis data yang digunakan adalah PLS dengan program Smart PLS 3.2.9. Dalam penelitian ini keempat variabel laten, yaitu: Pelatihan Kerja $\left(\mathrm{X}_{1}\right)$, Lingkungan Kerja $\left(\mathrm{X}_{2}\right)$, Motivasi $\left(\mathrm{Y}_{1}\right)$ dan Kinerja $\left(\mathrm{Y}_{2}\right)$ merupakan model pengukuran dengan indikator reflektif, sehingga dalam evaluasi model pengukuran dilakukan dengan memeriksa convergent dan discriminant validity dari indikator, serta composite reliability untuk blok indikator.

1. Hasil pemeriksaan outer model dapat diketahui bahwa dari enam indikator untuk mengukur variabel pelatihan kerja $\left(\mathrm{X}_{1}\right)$, hanya tiga yang memiliki nilai outer loading lebih besar dari 
0,50 dan T-Statistic berada diatas 1,96 yaitu: materi pelatihan, metode pelatihan dan tujuan pelatihan, ini berarti ketiga indikator tersebut valid untuk mengukur variabel pelatihan kerja. Indikator metode pelatihan merupakan ukuran terkuat pada variabel pelatihan kerja karena memiliki nilai outer loading paling besar $(0,865)$. Pemeriksaan outer model variabel lingkungan kerja $\left(\mathrm{X}_{2}\right)$ dapat diketahui bahwa dari tujuh indikator untuk mengukur variabel lingkungan kerja $\left(\mathrm{X}_{2}\right)$, hanya dua yang memiliki nilai outer loading lebih besar dari 0,50 dan T-Statistic berada diatas 1,96 yaitu: kemampuan dan hubungan pegawai, ini berarti kedua indikator tersebut valid untuk mengukur variabel lingkungan kerja. Indikator kemampuan pegawai merupakan ukuran terkuat pada variabel lingkungan kerja karena memiliki nilai outer loading paling besar $(0,814)$. Pemeriksaan outer model variabel motivasi $\left(\mathrm{Y}_{1}\right)$ dapat diketahui bahwa dari tiga indikator untuk mengukur variabel motivasi $\left(\mathrm{Y}_{1}\right)$, hanya dua yang memiliki nilai outer loading lebih besar dari 0,50 dan T-Statistic berada diatas 1,96 yaitu: arah perilaku dan tingkat usaha, ini berarti kedua indikator tersebut valid untuk mengukur variabel motivasi. Indikator tingkat usaha merupakan ukuran terkuat pada variabel motivasi karena memiliki nilai outer loading paling besar $(0,807)$. Pemeriksaan outer model dapat diketahui bahwa dari empat indikator untuk mengukur variabel kinerja $\left(\mathrm{Y}_{2}\right)$, hanya dua yang memiliki nilai outer loading lebih besar dari 0,50 dan T-Statistic berada diatas 1,96 yaitu: tingkat inisiatif dan kecekatan mental, ini berarti kedua indikator tersebut valid untuk mengukur variabel kinerja. Indikator kecekatan mental merupakan ukuran terkuat pada variabel kinerja karena memiliki nilai outer loading paling besar $(0,813)$.

2. Discriminant validity dilakukan dengan membandingkan nilai square root of average variance extracted ( $A V E$ ) setiap variabel laten dengan korelasi antar variabel laten lainnya dalam model. Nilai AVE yang direkomendasikan adalah lebih besar dari 0,50. Tabel 2 menunjukkan bahwa keempat variabel memiliki nilai AVE diatas 0,50 dan nilai $\sqrt{ }$ AVE untuk setiap variabel lebih tinggi dari koefisien korelasi antar variabel lainnya. Hasil yang diperoleh mengindikasikan bahwa model memiliki discriminant validity yang baik.

Tabel 2. Discriminant Validity

\begin{tabular}{lcccccc}
\hline \multicolumn{1}{c}{ Variabel } & \multirow{2}{*}{ AVE } & \multirow{2}{*}{ AVE } & \multicolumn{4}{c}{ Korelasi } \\
& & & $\mathrm{X}_{1}$ & $\mathrm{X}_{2}$ & $\mathrm{Y}_{1}$ & $\mathrm{Y}_{2}$ \\
\hline Pelatihan Kerja $\left(\mathrm{X}_{1}\right)$ & 0,589 & 0,767 & 1,000 & & & \\
Lingkungan Kerja $\left(\mathrm{X}_{2}\right)$ & 0,656 & 0,809 & 0,241 & 1,000 & & \\
Motivasi (Y & 0,589 & 0,767 & 0,328 & 0,572 & 1,000 & \\
Kinerja (Y & 0,683 & 0,826 & 0,410 & 0,488 & 0,454 & 1,000 \\
\hline Sumber: Data diolah & & & & & &
\end{tabular}


3. Composite Reliability bertujuan mengevaluasi nilai reliabilitas antara blok indikator dari konstruk yang membentuknya. Hasil composite reliability dikatakan baik apabila memiliki nilai diatas 0,70. Tabel 3 menujukkan nilai composite reliability dari keempat variabel laten telah berada diatas 0,70 , sehingga dapat disampaikan bahwa blok indikator reliabel mengukur variabel. Berdasarkan hasil evaluasi convergent dan discriminant validity masing-masing indikator, serta composite reliability untuk blok indikator, maka dapat disimpulkan bahwa indikator-indikator sebagai pengukur variabel laten masing-masing merupakan pengukur yang valid dan reliabel. Selanjutnya dilakukan analisis inner model untuk mengetahui kesesuaian model (goodness of fit model) pada penelitian ini.

Tabel 3. Composite Reliability

\begin{tabular}{ll}
\hline Variabel & Composite Reliability \\
\hline Pelatihan Kerja $\left(\mathrm{X}_{1}\right)$ & 0,866 \\
Lingkungan Kerja $\left(\mathrm{X}_{2}\right)$ & 0,792 \\
Motivasi $\left(\mathrm{Y}_{1}\right)$ & 0,741 \\
Kinerja $\left(\mathrm{Y}_{2}\right)$ & 0,740 \\
\hline
\end{tabular}

Sumber: Data diolah

Model struktural dievaluasi dengan memperhatikan $\mathrm{Q}^{2}$ predictive relevance model yang mengukur seberapa baik nilai observasi dihasilkan oleh model. $\mathrm{Q}^{2}$ didasarkan pada koefisien determinasi seluruh variabel dependen. Besaran $\mathrm{Q}^{2}$ memiliki nilai dengan rentang $0<\mathrm{Q}^{2}<1$, semakin mendekati nilai 1 berarti model semakin baik.

Tabel 4. Inner Model

\begin{tabular}{ccc}
\hline Model Struktural & \multicolumn{1}{c}{$\begin{array}{c}\text { Variabel Endogenus } \\
1\end{array}$} & R-square \\
2 & \multicolumn{1}{c}{ Motivasi $\left(\mathrm{Y}_{1}\right)$} & 0,366 \\
Kinerja $\left(\mathrm{Y}_{2}\right)$ & 0,350 \\
\hline Kalkulasi : $\mathrm{Q}^{2}=1-\left(1-\mathrm{R}_{1}^{2}\right)\left(1-\mathrm{R}_{2}^{2}\right)$ & \\
$\mathrm{Q}^{2}=1-(1-0,366)(1-0,350)$ & \\
$\mathrm{Q}^{2}=1-(0,634)(0,650)$ & \\
$\mathrm{Q}^{2}=1-0,4121$ & \\
$\mathrm{Q}^{2}=0,5879$ & \\
\hline
\end{tabular}

Sumber: Data diolah

Dalam model structural ini, terdapat dua variabel endogenus (dependen), yaitu Motivasi $\left(\mathrm{Y}_{1}\right)$ dan Kinerja $\left(\mathrm{Y}_{2}\right)$. Hasil evaluasi model structural terbukti nilai $\mathrm{Q}^{2}$ sebesar 0,5879 mendekati angka 1. Dengan demikian, hasil evaluasi ini memberi bukti bahwa model struktural memiliki kesesuaian (goodness of fit model) yang cukup baik. Hasil ini bermakna bahwa informasi yang terkandung dalam data 58,79\% dapat dijelaskan oleh model, sedangkan sisanya 41,21\% dijelaskan oleh error dan variabel lain yang belum terdapat dalam model. 
Tabel 5. Hasil Pengujian Hipotesis

\begin{tabular}{clcccc}
\hline No & Hubungan Antar Variabel & $\begin{array}{l}\text { Koefisien Jalur } \\
\text { (Bootstrapping) }\end{array}$ & T-Statistics & P Values & Keterangan \\
\hline 1 & $\begin{array}{l}\text { Pelatihan Kerja }\left(\mathrm{X}_{1}\right) \rightarrow \\
\text { Motivasi }\left(\mathrm{Y}_{1}\right)\end{array}$ & 0,202 & 1,574 & 0,116 & Tidak \\
2 & $\begin{array}{l}\text { Lingkungan Kerja }\left(\mathrm{X}_{2}\right) \rightarrow \\
\text { Signifikan } \\
\text { Motivasi }\left(\mathrm{Y}_{1}\right)\end{array}$ & 0,523 & 3,806 & 0,000 & Signifikan \\
3 & $\begin{array}{l}\text { Pelatihan Kerja }\left(\mathrm{X}_{1}\right) \rightarrow \\
\text { Kinerja }\left(\mathrm{Y}_{2}\right)\end{array}$ & 0,274 & 2,332 & 0,020 & Signifikan \\
4 & $\begin{array}{l}\text { Lingkungan Kerja }\left(\mathrm{X}_{2}\right) \rightarrow \\
\text { Kinerja }\left(\mathrm{Y}_{2}\right)\end{array}$ & 0,317 & 1,736 & 0,083 & $\begin{array}{l}\text { Tidak } \\
\text { Signifikan }\end{array}$ \\
6 & $\begin{array}{l}\text { Motivasi }\left(\mathrm{Y}_{1}\right) \rightarrow \text { Kinerja } \\
\text { (Y) }\end{array}$ & 0,183 & 0,987 & 0,324 & $\begin{array}{l}\text { Tidak } \\
\text { Signifikan } \\
\text { Pelatihan Kerja }\left(\mathrm{X}_{1}\right) \rightarrow\end{array}$ \\
$\begin{array}{l}\text { Motivasi }\left(\mathrm{Y}_{1}\right) \rightarrow \text { Kinerja } \\
\text { (Y) }\end{array}$ & 0,096 & 0,909 & 0,364 & $\begin{array}{l}\text { Tidak } \\
\text { Signifikan }\end{array}$ \\
$\begin{array}{l}\text { Lingkungan Kerja }\left(\mathrm{X}_{2}\right) \rightarrow \\
\text { Motivasi }\left(\mathrm{Y}_{1}\right) \rightarrow \text { Kinerja } \\
\left(\mathrm{Y}_{2}\right)\end{array}$ & 0,037 & 0,746 & 0,456 & $\begin{array}{l}\text { Tidak } \\
\text { Signifikan }\end{array}$ \\
\hline
\end{tabular}

Sumber: Data diolah

Dari tabel 5 dapat ditentukan hasil pengujian hipotesis sebagai berikut :

1. Pelatihan Kerja $\left(\mathrm{X}_{1}\right)$ terbukti berpengaruh positif tetapi tidak signifikan terhadap Motivasi (Y) pegawai medis Instalasi Rawat Inap B RSUP Sanglah Denpasar. Hasil ini ditunjukkan oleh koefisien jalur yang bernilai positif sebesar 0,202 dengan T Statistics $=1,574<1,96$ dan $\mathrm{P}$ Values 0,116 > 0,05. Hasil penelitian ini sejalan dengan penelitian yang dilakukan oleh (Yunior, 2018), bahwa pelatihan tidak memiliki pengaruh yang signifikan terhadap motivasi kerja. Begitu pula penelitian yang dilakukan oleh (Sumbogo \& Diposumarto, 2017), bahwa pelatihan tidak berpengaruh signifikan terhadap motivasi. Hasil penelitian ini tidak sejalan dengan penelitian yang dilakukan oleh (Lestari \& Hadiyanti, 2019), yang menyatakan bahwa Pelatihan berpengaruh signifikan terhadap motivasi kerja karyawan.

2. Lingkungan Kerja $\left(\mathrm{X}_{2}\right)$ terbukti berpengaruh positif dan signifikan terhadap Motivasi ( $\left.\mathrm{Y}_{1}\right)$ pegawai medis Instalasi Rawat Inap B RSUP Sanglah Denpasar. Hasil ini ditunjukkan oleh koefisien jalur yang bernilai positif sebesar 0,523 dengan T Statistics $=3,806>1,96$ dan $\mathrm{P}$ Values $0,000<0,05$. Hasil penelitian ini sejalan dengan penelitian yang dilakukan oleh (Moulana et al., 2017), bahwa lingkungan kerja berpengaruh positif dan signifikan terhadap motivasi kerja.

3. Pelatihan Kerja $\left(\mathrm{X}_{1}\right)$ terbukti berpengaruh positif dan signifikan terhadap Kinerja $\left(\mathrm{Y}_{2}\right)$ pegawai medis Instalasi Rawat Inap B RSUP Sanglah Denpasar. Hasil ini ditunjukkan oleh koefisien jalur yang bernilai positif sebesar 0,274 dengan $T$ Statistics $=2,332>1,96$ dan $\mathrm{P}$ Values $0,020<0,05$. Hasil penelitian ini sejalan dengan penelitian (Paramarta \& Kasih, 2018), 
bahwa pelatihan berpengaruh positif dan signifikan terhadap kinerja perawat Instalasi Bedah Sentral RSUP Sanglah Denpasar. Begitu pula dengan penelitian yang dilakukan oleh (Andayani \& Makian, 2016), bahwa pelatihan berpengaruh positif dan signifikan secara langsung terhadap kinerja karyawan. Hasil penelitian ini tidak sejalan dengan penelitian yang dilakukan oleh (Randy, 2016), yang menyatakan bahwa pelatihan kerja berpengaruh negatif terhadap kinerja karyawan pada PT. Arita Prima Indonesia, Tbk di Batam. (Ongalo \& Tari, 2015), juga menyatakan bahwa pelatihan memiliki efek negatif terhadap kinerja karyawan pada Perusahaan Pembangkit Listrik dan Distribusi di Kenya.

4. Lingkungan Kerja $\left(\mathrm{X}_{2}\right)$ terbukti berpengaruh positif tetapi tidak signifikan terhadap Kinerja $\left(\mathrm{Y}_{2}\right)$ pegawai medis Instalasi Rawat Inap B RSUP Sanglah Denpasar. Hasil ini ditunjukkan oleh koefisien jalur yang bernilai positif sebesar 0,317 dengan T Statistics = 1,736 < 1,96 dan P Values 0,083 > 0,05. Hasil penelitian ini sejalan dengan (Mamangkey et al., 2015), bahwa lingkungan kerja tidak berpengaruh terhadap kinerja karyawan pada PT. Bangun Wenang Beverages Company Manado. Begitu pula penelitian yang dilakukan oleh (Logahan et al., 2012), bahwa Lingkungan kerja tidak memiliki pengaruh yang signifikan terhadap kinerja karyawan di CV Mum Indonesia. Hasil penelitian ini tidak sejalan dengan penelitian yang dilakukan oleh (Chandra \& Setiawan, 2018), bahwa Lingkungan kerja berpengaruh positif dan signifikan terhadap semangat kerja karyawan pada PT. Diantri. (Pratama \& Wismar'ein, 2018), juga menyatakan Lingkungan kerja terbukti memiliki pengaruh positif dan signifikan terhadap kinerja karyawan.

5. Motivasi $\left(\mathrm{Y}_{1}\right)$ terbukti berpengaruh positif tetapi tidak signifikan terhadap Kinerja $\left(\mathrm{Y}_{2}\right)$ pegawai medis Instalasi Rawat Inap B RSUP Sanglah Denpasar. Hasil ini ditunjukkan oleh koefisien jalur yang bernilai positif sebesar 0,183 dengan T Statistics $=0,987<1,96$ dan $\mathrm{P}$ Values $0,324>0,05$. Hasil penelitian ini sejalan dengan penelitian yang dilakukan oleh (Vanli, 2019), bahwa motivasi berpengaruh positif dan tidak signifikan terhadap kinerja perusahaan pada PT. BUMP Kota Solok. Begitu pula penelitian yang dilakukan oleh (Murti \& Srimulyani, 2013), bahwa motivasi tidak berpengaruh signifikan terhadap kinerja pegawai. Dan juga penelitian Utami dan Astakoni (2020), yang menyatakan motivasi berpengaruh positif tetapi tidak signifikan terhadap kinerja karyawan. Hasil penelitian ini tidak sejalan dengan penelitian yang dilakukan oleh (Paramarta \& Kasih, 2018), bahwa motivasi berpengaruh terhadap kinerja perawat Instalasi Bedah Sentral RSUP Sanglah Denpasar. Penelitian ini juga tidak sejalan dengan penelitian yang dilakukan oleh (Andayani \& Makian, 2016), bahwa motivasi kerja berpengaruh positif dan signifikan secara langsung terhadap kinerja karyawan. 
6. Pelatihan Kerja $\left(\mathrm{X}_{1}\right)$ berpengaruh positif tetapi tidak signifikan terhadap Kinerja $\left(\mathrm{Y}_{2}\right)$ melalui Motivasi $\left(\mathrm{Y}_{1}\right)$ pegawai medis Instalasi Rawat Inap B RSUP Sanglah Denpasar. Hasil ini ditunjukkan oleh koefisien jalur yang bernilai positif sebesar 0,096 dengan T Statistics $=0.909$ $<$ 1,96 dan P Values 0,364 > 0,05. Hasil penelitian ini menunjukkan bahwa meningkatnya motivasi kerja pegawai medis Instalasi Rawat Inap B RSUP Sanglah Denpasar tidak mampu memediasi pengaruh langsung antara Pelatihan Kerja terhadap Kinerja pegawai medis Instalasi Rawat Inap B RSUP Sanglah Denpasar.

7. Lingkungan Kerja $\left(\mathrm{X}_{2}\right)$ berpengaruh positif tetapi tidak signifikan terhadap Kinerja $\left(\mathrm{Y}_{2}\right)$ melalui Motivasi ( $\left.\mathrm{Y}_{1}\right)$ pegawai medis Instalasi Rawat Inap B RSUP Sanglah Denpasar. Hasil ini ditunjukkan oleh koefisien jalur yang bernilai positif sebesar 0,037 dengan T Statistics $=$ $0,746<1,96$ dan $\mathrm{P}$ Values $0,456>0,05$. Hasil penelitian ini menunjukkan bahwa meningkatnya motivasi kerja pegawai medis Instalasi Rawat Inap B RSUP Sanglah Denpasar tidak mampu memediasi pengaruh langsung antara Lingkungan Kerja terhadap Kinerja pegawai medis Instalasi Rawat Inap B RSUP Sanglah Denpasar.

Berdasarkan hasil pengujian hipotesis-hipotesis yang telah diuraikan tersebut, maka dapat disusun diagram jalur/model struktural penelitian seperti pada gambar 2 berikut ini:

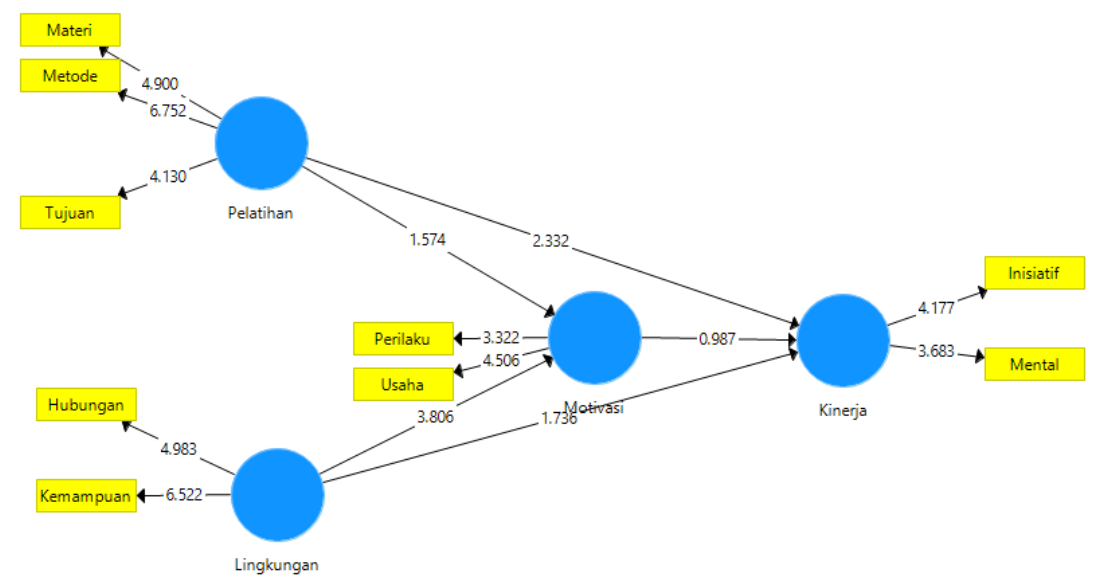

Gambar 2. Model Struktural Penelitian

\section{Simpulan}

Berdasarkan hasil analisis dan pembahasan yang telah dilakukan dalam penelitian ini, maka dapat diperoleh simpulan sebagai berikut:

1. Pelatihan Kerja $\left(\mathrm{X}_{1}\right)$ terbukti berpengaruh positif tetapi tidak signifikan terhadap Motivasi (Y) pegawai medis Instalasi Rawat Inap B RSUP Sanglah Denpasar. Hasil ini menunjukkan bahwa semakin banyak diberikan pelatihan kerja kepada pegawai medis Instalasi Rawat Inap 
B RSUP Sanglah Denpasar maka akan semakin meningkatkan motivasi kerja pegawai medis Instalasi Rawat Inap B RSUP Sanglah Denpasar.

2. Lingkungan Kerja $\left(\mathrm{X}_{2}\right)$ terbukti berpengaruh positif dan signifikan terhadap Motivasi $\left(\mathrm{Y}_{1}\right)$ pegawai medis Instalasi Rawat Inap B RSUP Sanglah Denpasar. Hasil ini menunjukkan bahwa semakin baik kondisi Lingkungan Kerja pegawai medis Instalasi Rawat Inap B RSUP Sanglah Denpasar maka akan semakin meningkatkan motivasi kerja pegawai medis Instalasi Rawat Inap B RSUP Sanglah Denpasar.

3. Pelatihan Kerja $\left(\mathrm{X}_{1}\right)$ terbukti berpengaruh positif dan signifikan terhadap Kinerja $\left(\mathrm{Y}_{2}\right)$ pegawai medis Instalasi Rawat Inap B RSUP Sanglah Denpasar. Hasil ini menunjukkan bahwa semakin banyak diberikan pelatihan kerja kepada pegawai medis Instalasi Rawat Inap B RSUP Sanglah Denpasar maka akan semakin meningkatkan Kinerja pegawai medis Instalasi Rawat Inap B RSUP Sanglah Denpasar.

4. Lingkungan Kerja $\left(\mathrm{X}_{2}\right)$ terbukti berpengaruh positif tetapi tidak signifikan terhadap Kinerja $\left(\mathrm{Y}_{2}\right)$ pegawai medis Instalasi Rawat Inap B RSUP Sanglah Denpasar. Hasil ini menunjukkan bahwa semakin baik kondisi Lingkungan Kerja pegawai medis Instalasi Rawat Inap B RSUP Sanglah Denpasar maka akan semakin meningkatkan Kinerja pegawai medis Instalasi Rawat Inap B RSUP Sanglah Denpasar.

5. Motivasi $\left(\mathrm{Y}_{1}\right)$ terbukti berpengaruh positif tetapi tidak signifikan terhadap Kinerja $\left(\mathrm{Y}_{2}\right)$ pegawai medis Instalasi Rawat Inap B RSUP Sanglah Denpasar. Hasil ini menunjukkan bahwa semakin tinggi motivasi kerja pegawai medis Instalasi Rawat Inap B RSUP Sanglah Denpasar maka akan semakin meningkatkan Kinerja pegawai medis Instalasi Rawat Inap B RSUP Sanglah Denpasar.

6. Pelatihan Kerja $\left(\mathrm{X}_{1}\right)$ berpengaruh positif tetapi tidak signifikan terhadap Kinerja $\left(\mathrm{Y}_{2}\right)$ melalui Motivasi $\left(\mathrm{Y}_{1}\right)$ pegawai medis Instalasi Rawat Inap B RSUP Sanglah Denpasar. Hasil penelitian ini menunjukkan bahwa meningkatnya motivasi kerja pegawai medis Instalasi Rawat Inap B RSUP Sanglah Denpasar tidak mampu memediasi pengaruh langsung antara Pelatihan Kerja terhadap Kinerja pegawai medis Instalasi Rawat Inap B RSUP Sanglah Denpasar.

7. Lingkungan Kerja $\left(\mathrm{X}_{2}\right)$ berpengaruh positif tetapi tidak signifikan terhadap Kinerja $\left(\mathrm{Y}_{2}\right)$ melalui Motivasi ( $\left.\mathrm{Y}_{1}\right)$ pegawai medis Instalasi Rawat Inap B RSUP Sanglah Denpasar. Hasil penelitian ini menunjukkan bahwa meningkatnya motivasi kerja pegawai medis Instalasi Rawat Inap B RSUP Sanglah Denpasar tidak mampu memediasi pengaruh langsung antara Lingkungan Kerja terhadap Kinerja pegawai medis Instalasi Rawat Inap B RSUP Sanglah Denpasar. 
Implikasi yang dapat diambil dari penelitian ini antara lain :

1. Penelitian selanjutnya hendaknya melakukan penelitian diberbagai sektor/unit/bagian. Sehingga, hasil penelitian nantinya dapat mempersentasikan dan juga dapat digeneralisasikan pada semua karyawan disetiap sektor/unit/bagian yang ada.

2. Dalam peningkatan kinerja pegawai medis, sebaiknya organisasi harus melakukan pembaharuan dalam hal pelatihan, lingkungan kerja maupun motivasi untuk mendapatkan kinerja yang diharapkan.

3. Bagi peneliti selanjutnya, dapat mereplikasi model penelitian ini melalui pendekatan longitudinal (dari waktu ke waktu) dan memungkinkan digunakan pada organisasi/perusahaan lainnya. Selain itu peneliti mendatang dapat memodifikasi model penelitian dengan menambahkan variabel-variabel lain yang disesuaikan dengan kondisi organisasi/perusahaan tempat melakukan penelitian.

\section{Daftar Pustaka}

Abdillah, W., \& Jogiyanto. (2015). Partial Least Square (PLS), Alternatif Structural Equation Modeling (SEM) Dalam Penelitian Bisnis (1st ed.).

Andayani, N. R., \& Makian, P. (2016). Pengaruh Pelatihan Kerja dan Motivasi Kerja Terhadap kinerja Karyawan Bagian PT. PCI Elektronik International (Studi pada Karyawan PT. PCI Elektronik Internasional). Jurnal Akuntansi, Ekonomi Dan Manajemen Bisnis, 4(1), 41-46.

Anugrah, P. T., \& Abdurrahman, D. (2019). Pengaruh Motivasi Kerja Dan Lingkungan Kerja terhadap Kinerja Karyawan pada Lembaga Penyiaran Publik Radio Republik Indonesia Bandung. Prosiding Manajemen, 5(1), 727-734.

Basori, M. A. N., Prahiawan, W., \& Daenulhay. (2017). Pengaruh Kompetensi Karyawan dan Lingkungan Kerja Terhadap Kinerja Karyawan Melalui Motivasi Kerja Sebagai Variabel Intervening (Studi Pada PT. Krakatau Bandar Samudera). Jurnal Riset Bisnis Dan Manajemen Tirtayasa, 1(2), 149-157.

Batjo, N., \& Shaleh, D. M. (2018). Manajemen Sumber Daya Manusia (Humaidi \& Mirnawati (eds.); 1st ed.). Aksara Timur.

Budianto, A. A. T., \& Katini, A. (2015). Pengaruh Lingkungan Kerja Terhadap Kinerja Pegawai Pada PT Perusahaan Gas Negara (Persero) Tbk SBU Distribusi Wilayah Jakarta. Jurnal Ilmiah Prodi Manajemen Universitas Pamulang, 3(1), 100-124. https://doi.org/10.37751/parameter.v4i2.42.

Carsel HR, H. S. (2018). Metodologi Penelitian Kesehatan dan Pendidikan (A. Adriani (ed.); 1st ed.). Penebar Media Pustaka. https://doi.org/KDT.

Chandra, D. A., \& Setiawan, R. (2018). Pengaruh Lingkungan Kerja dan Iklim Organisasi Terhadap Semangat Kerja Karyawan PT. Diantri. Jurnal Mahasiswa Manajemen Bisnis, 6(1), $1-8$.

Dewi, S. K., \& Frianto, A. (2013). Pengaruh Lingkungan Kerja Terhadap Kinerja Karyawan Melalui Motivasi. Jurnal Ilmiah Manajemen, 1(4). http://journal.uta45jakarta.ac.id/index.php/MSE/article/view/769.

Diansyah, \& Saepul, T. (2017). Pengaruh Pelatihan dan Kompensasi Terhadap Kinerja Karyawan Dengan Motivasi Sebagai Variabel Intervening Pada Mikro Laju Cluster Jakarta 2 PT. Bank CIMB Niaga TBK. Jurnal Online Internasional \& Nasional, 20(1), 1-14. http://journal.uta45jakarta.ac.id/index.php/MSE/article/view/769.

Duli, N. (2019). Metodologi Penelitian Kuantitatif: Beberapa Konsep Dasar Untuk Penulisan 
Skripsi \& Analisis Data Dengan SPSS (1st ed.). CV Budi Utama.

Elbadiansyah. (2019). Manajemen Sumber Daya Manusia (C. I. Gunawan (ed.); 1st ed.). CV IRDH.

Herani, J. (2018). Pengaruh Kualitas Pelayanan Terhadap Loyalitas Merek Melalui Kepuasan Pelanggan (Studi pada Pelanggan Bengkel Yamaha 2 Mei Bandar Lampung). 3(1). https://doi.org/10.1017/CBO9781107415324.004.

Iskandar, \& Yuhansyah. (2018). Pengaruh Motivasi \& Ketidakamanan Kerja Terhadap Penilaian Kerja Yang Berdampak Kepada Kepuasan Kerja (1st ed.). Media Sahabat Cendekia.

Khrisna. (2017). Sejarah Model Persamaan Struktural, Structural Equation Modeling (SEM). Data Riset.

Kurniasari, R. (2018). Pemberian Motivasi serta Dampaknya Terhadap Kinerja Karyawan Pada Perusahaan Telekomunikasi Jakarta. Jurnal Sekretari Dan Manajemen, 2(1), 32-39.

Kurniasari, R., Oktiani, N., \& Ramadhanti, G. (2018). Pelatihan Kerja dalam Usaha Meningkatkan Kinerja Karyawan Baru Pada PT Kusumatama Mitra Selaras Jakarta. Jurnal Sekretari Dan Manajemen, 2(2), 239-246. https://doi.org/10.31294/widyacipta.v2i2.4140.

Lestari, M. F., \& Hadiyanti, S. U. E. (2019). Pengaruh Pelatihan Terhadap Motivasi Kerja Karyawan di PT Harmoni Mitra Utama Cabang Samarinda. Jurnal Ekonomi Dan Manajemen, 13(2), 92-103.

Liawandy, F., Indarti, S., \& Marzolina. (2014). Pengaruh Disiplin Kerja dan Lingkungan Kerja Terhadap Kinerja Karyawan Bagian Produksi PT. Nafal Tiara Abadi Pekanbaru. Jurnal Online Mahasiswa Fakultas Ekonomi, 1(2), 1-15.

Logahan, J. M., Tjoe, T. F., \& Naga. (2012). Analisis Pengaruh Lingkungan Kerja dan Pemberian Kompensasi terhadap Kinerja Karyawan CV Mum Indonesia. Binus Business Review, 3(1), 573-586.

Lusri, L., \& Siagian, H. (2017). Pengaruh Motivasi Kerja Terhadap Kinerja Karyawan Melalui Kepuasan Kerja Sebagai Variabel Mediasi Pada Karyawan PT. Borwita Citra Prima Surabaya. Jurnal Mahasiswa Manajemen Bisnis, 5(1), 1-8.

Mamangkey, T. J., Tumbel, A., \& Uhing, Y. (2015). Pengaruh Pelatihan, Pengalaman Dan Lingkungan Kerja Terhadap Kinerja Karyawan Pada Pt. Bangun Wenang Beverages Company Manado. Jurnal Riset Ekonomi, Manajemen, Bisnis Dan Akuntansi, 3(1), 737-747.

Maulidah, S. (2012). Pengantar Manajemen Agribisnis (T. UB Pres (ed.); 1st ed.). Universitas Brawijaya Pres (UB Press). https://doi.org/KTD.

Moulana, F., Sunuharyo, B. S., \& Utami, H. N. (2017). Pengaruh Lingkungan Kerja Terhadap Kinerja Karyawan Melalui Variabel Mediator Motivasi Kerja (Studi pada Karyawan PT. Telkom Indonesia, Tbk Witel Jatim Selatan, Jalan A. Yani, Malang). Jurnal Administrasi Bisnis (JAB), 44(1), 178-185.

Murti, H., \& Srimulyani, V. A. (2013). Pengaruh Motivasi Terhadap Kinerja Pegawai Dengan Variabel Pemediasi Kepuasan Kerja Pada PDAM Kota Madiun. Jurnal Riset Manajemen Dan Akuntansi, 1(1), 10-17.

Norianggono, Y. chresstela P., Hamid, D., \& Ruhana, I. (2014). Pengaruh Lingkungan Kerja Fisik dan Non Fisik Terhadap Kinerja Karyawan (Studi Pada Karyawan PT. Telkomsel Area III Jawa-Bali Nusra di Surabaya). Jurnal Administrasi Bisnis, 8(2), 1-10.

Ongalo, E. A., \& Tari, D. J. (2015). Effect of Employee Motivation Strategies on Organizational Performance : A Case of Electricity Generating and Distribution Firms in Kenya. European Journal of Business and Management, 7(8), 55-66.

Paramarta, W. A., \& Kasih, I. G. A. P. (2018). Pelatihan dan Motivasi Pengaruhnya Terhadap Kinerja Perawat Instalasi Bedah Sentral RSUP Sanglah Denpasar dengan Employee Engagement Sebagai Variabel Intervening. Jurnal Ilmu Manajemen, 8(2), 137-170. http://ejournal.unmas.ac.id/index.php/juima/article/view/295. 
Pareraway, A. S., Kojo, C., \& Roring, F. (2018). Pengaruh Lingkungan Kerja, Pelatihan, dan Pemberdayaan SDM Terhadap Kepuasan Kerja Karyawan PT. PLN (Persero) Wilayah Suluttenggo. Jurnal Riset Ekonomi, Manajemen, Bisnis Dan Akuntansi, 6(3), 1828-1837.

Prasetyo, R., \& Nurbiyati, T. (2019). Analisis Kinerja: Training, Lingkungan Kerja, Budaya Organisasi Dan Kepuasan Kerja. Kajian Bisnis, 27(2), 147-174. https://doi.org/10.32477/jkb.v27i2.347.

Pratama, Y. F., \& Wismar'ein, D. (2018). Pengaruh Pelatihan dan Lingkungan Kerja Terhadap Kinerja Karyawan. Business Management Analysis Journal, 1(1), 26-36. https://doi.org/10.24176/bmaj.v1i1.2686.

Putra, I. P., Sitiari, W., \& Sara, I. M. (2017). Pengaruh Pelatihan, Motivasi, Lingkungan Kerja dan Motivasi terhadap Kinerja Karyawan pada Rumah Makan Warung Mina Denpasar. Jurnal Ekonomi \& Bisnis, 4(2), 89-100. https://doi.org/10.22225/jj.4.2.308.89.

Putri, N. M. D. K. (2019). Peran Semangat Kerja Memediasi Pengaruh Lingkungan Kerja Terhadap Kinerja Pegawai Dinas Kesehatan Kabupaten Tabanan, Bali. Widya Manajemen, 1(2), 60-76. https://doi.org/10.32795/widyamanajemen.v1i2.356

Ramadhan, G. (2018). Analisis Hubungan Profesionalisme Kerja Pegawai Terhadap Kinerja Pegawai Pada Kantor Dinas Kependudukan Dan Pencatatan Sipil Kota Banjarmasin. Jurnal Administrasi Publik, 1(15), 1-9.

Randy. (2016). Pengaruh Pelatihan Kerja dan Pengembangan SDM Terhadap Kinerja Karyawan Pada PT. ARITA Prima Indonesia, TBK di Batam. Technology, 1(1), 1-53.

Rikomah, S. E. (2017). Farmasi Rumah Sakit (1st ed.). CV Budi Utama.

Sari, T. T. (2020). Lingkungan Kerja Terhadap Kinerja Karyawan PT . Telkom Witel Yogyakarta. Kajian Bisnis, 28(1), 71-88.

Sudaryo, D. Y., Aribowo, D. A., \& Ayu Sofiati, D. N. (2018). Manajemen Sumber Daya Manusia, Kompensasi Tidak Langsung Dan Lingkungan Kerja Fisik (T. Erang (ed.); 1st ed.). Penerbit ANDI (Anggota IKAPI).

Sudaryono. (2016). Metode Penelitian Pendidikan (1st ed.). KENCANA (Prenadamedia Group). https://doi.org/KDT.

Sulaksono, H. (2015). Budaya Organisasi Dan Kinerja (1st ed.). CV Budi Utama.

Sumbogo, I. A., \& Diposumarto, N. S. (2017). Pengaruh Kompetensi dan Pelatihan Terhadap Kinerja Reporter, dengan Motivasi Sebagai Variabel Mediasi di PT SWC. Jurnal Riset Manajemen Dan Bisnis (JRMB), 2(3), 331-340.

Susan, E. (2019). MANAJEMEN SUMBER DAYA MANUSIA. Adaara: Jurnal Manajemen Pendidikan Islam, 9(2), 952-962. https://doi.org/10.35673/ajmpi.v9i2.429.

Sutoro, M. (2019). Pengaruh Pengembangan Karir Terhadap Kinerja Karyawan Pada PT. BCA Finance Jakarta. Jurnal Ekonomi Efektif, 2.

Utami, N. M. S., \& Astakoni, I. M. P. (2020). Peran Gender Sebagai Group Pada Kepemimpinan Path Goal Dan Motivasi Sebagai Determinan Kinerja Guru. Widya Manajemen, 2(1), 36-46. https://doi.org/10.32795/widyamanajemen.v2i1.548

Vanli, G. (2019). Pengaruh Motivasi Kerja, Kepemimpinan dan Budaya Organisasi Terhadap Kepuasan Kerja Karyawan Serta Dampaknya Pada Kinerja Perusahaan (Studi Kasus Pada PT. BUMP Kota Solok) [Universitas Putra Indonesia "YPTK" Padang]. http://repository.upiyptk.ac.id/id/eprint/2110.

Widodo, S. E. (2015). Manajemen Pengembangan Sumber Daya Manusia (1st ed.). Pustaka Belajar.

Yanti, Haryono, A. T., \& Minarsih, M. M. (2015). Pengaruh Kompensasi, Motivasi Kerja, Lingkungan Kerja dan Disiplin Terhadap Kinerja Karyawan pada CV Koperasi Puri Kencana Taxi Semarang. Journal of Management, 1(1), 1-23. http://jurnal.unpand.ac.id/index.php/MS/article/view/271.

Yenny. (2018). Pengaruh Kompetensi, Motivasi dan Disiplin Kerja Terhadap Kinerja Guru pada 
Yayasan Pendidikan Imanuel Palu. Jurnal Katalogis, 6(2), 98-105.

Yunior, D. R. (2018). Pengaruh Pelatihan Terhadap Motivasi Kerja Pegawai Pada Balai Besar Pendidikan dan Pelatihan Kesejahteraan Sosial Regional V Sulawesi di Kota Makassar. Management. 